\title{
Effect of Humidity on the Amount of Water Collected from Air-Condition Systems: Experimental Approach
}

\author{
Husham M. Ahmed \\ College of Engineering, AMA International University - Bahrain
}

\begin{abstract}
More than $60 \%$ of the total electricity produced in the Kingdom of Bahrain and other Arabian Gulf Countries in the summer seasons are being used to meet air conditioning demands. The process involves the extraction of heat as well as the extraction of moisture (humidity) from the air. Those and many other countries, with hot and humid environment, usually have severe water scarcity and poor endowment of water resources. Harvesting and collecting of the by-product condensate water from air conditioning system provide a good alternative water supply, mainly for non drinking requirements. In this study, the effect of atmospheric (outside) humidity and humidity inside the buildings (indoor) on the amount of water collected from the air conditioning system, as a byproduct, have been studied experimentally. The data has been collected for two years (2017 \& 2018) during the period from April to October in the Kingdom of Bahrain for different days on hourly basis from two tons of refrigeration split unit system. Atmospheric humidity, the room inside humidity, the atmospheric temperature, and the room temperature, have been recorded. Respected dew points have been calculated. The measured atmospheric relative humidity was compared to the officially recorded relative humidity at Bahrain Airport. It has been found to perfectly agree with each other with a mean deviation of $0.44 \%$ and $1.27 \%$ for the two consecutive years. The collected average amounts of water from the air conditioning system for the two years and for each month is fully consistent and reflect the effect of humidity in form of liner relationship.
\end{abstract}

Keywords: Water resource, air conditioning system, humidification-dehumidification

DOI: $10.7176 / \mathrm{JETP} / 9-7-05$

Publication date:October $31^{\text {st }} 2019$

\section{Introduction}

Freshwater is decreasing every day as demand and pollution increases and climate changes and in particular in hot regions. This created enormous strain on freshwater supplies Bagheri (2018). With an estimated 12,800 trillion liters of renewable water available in the atmosphere, atmospheric water harvesting has the potential to be a viable solution to address some of the global needs for fresh water; especially in warm regions were humidity is high such as the coastal areas Milani et al (2014). The Kingdom of Bahrain and other Arabian Gulf countries, being situated in one of the most arid regions of the world have an extremely poor endowment of water resources with high humidity round the year Al-Zubari et al. (2018). Those and many other counties heavily rely on air conditioning systems for thermal comfort especially during the hot summer seasons which extend usually for more than 7 months. In fact more than $60 \%$ of the electrical energy produced in those countries is used to meet the air conditioning demands. Fortunately, the by-product of those air condition systems is pure fresh water Attalla and Hunt (2016). Therefore, harvesting water via dehumidification from atmospheric air by condensation was always regarded by many investigators as a good solution to provide fresh and clean water source. The process involves cooling down the atmospheric air to the dew point temperature for dehumidification. This process require high amount of energy which make it not economic Ghimire et al. (2019).

Ghimire et al. (2019) presented an assessment study about air conditioning and rain water harvesting for nonpotable water reuse in commercial buildings in two states of the United States of America. The research reported that the water collected from San Francisco's Air Conditioning System in 19-story building outperformed the water collected from the Rain water collection system 51- 83\% due to the larger volume of Francisco's Air Conditioning System. In a for story building in Washington D.C. state, the water collected from rain water collection system outperformed the air conditioning collection system by $45-80 \%$. They related their results to the Local climatic conditions, rainfall, and humidity. Dalai et al. (2017) conducted an experimental study of the performance of an air conditioning system, using the concept of Humidification - dehumidification technique. The technique relies on utilizing the moisture present in atmospheric air and to increase its content to certain extent. It is observed from the study that the water extracted through this technique is of good standard and can be used for drinking and other purposes. It is also observed from the study that the amount of water collected depends on volume of flow rate, cooling coil, capacity, humidity, heat transfer coefficient and time of residence of air inside the window air conditioner. The average water collection rate was $0.3 \mathrm{ml} / \mathrm{s}$. Painter (2009) conducted an investigation on a laboratory building as a case study. The study suggested that condensate collection, from the air conditioning units installed in the building, could provide for the building's total water closet and urinal needs as well as a large part of the building's cooling tower demand. Loveless et al. (2013) considered the collection of condensate water from large air conditioning units as a possible method to alleviate water scarcity issues. It is 
observed that the quality of condensate water collected from various locations and types of air conditioners was very high with conductivities reaching as low as $18 \mu \mathrm{S} / \mathrm{cm}$ and turbidity's of $0.041 \mathrm{NTU}$.

Thus, in this study, the effect of atmospheric and indoor (room) relative humidity will be evaluated experimentally, discussed and analyzed in order to model a relationship between humidity and the amount of condensed water can be obtained from a specific air condition system capacity per day.

\section{Methodology}

Almost all houses, offices, malls, industry, and all other rooms and indoor spaces use air condition for thermal comfort in Bahrain, Gulf countries, and many other countries. The by-product of operating these huge number of air condition systems is enormous amount of pure fresh water. In this study, an attempt to find a relationship on the effect of relative humidity on the amount produced from the air condition systems. Therefore an actual circumstance of operating two tons of refrigeration split air conditioning unit has been practically tested. Condensed water were collected on hourly basis for different days for two years (2017 \& 2018) over seven month periods (May, June, July, August and September) representing the hot season while (April - October) representing the relatively moderate season, in Bahrain where air conditioning systems heavily and intensively used. During the data collection, Atmospheric (outside) temperature, Room (inside) temperature, outside and inside relative humidity have been recorded. The Dew point temperature has been calculated.

\section{Results and Discussions}

The results presented in this section were obtained for Bahrain climate conditions. The effect of humidity on the amount of condensate water collected from a split unit of 2 tons of refrigeration have be studied and analyzed.

The average amount of condensate collected for the seven months for 2017 was $2.036 \mathrm{l} / \mathrm{hr}$ and for 2018 was 2.065 $1 / \mathrm{hr}$ which is very close results and reflects consistency in relation between humidity, temperature and condensation. Table 1 shows the collected amount per month for the two consecutive years.

Table 1. The amount of condensed water collected per month for the two years.

\begin{tabular}{|c|l|l|l|l|l|l|l|l|}
\hline Month & April & May & June & July & Aug. & Sept & Oct. & Average \\
\hline Average (2017) L/h & 1.75 & 1.64 & 1.83 & 2.2 & 2.37 & $\mathbf{2 . 2 8}$ & $\mathbf{2 . 1 8}$ & $\mathbf{2 . 0 3 6}$ \\
\hline Average (2018) L/h & 1.91 & 1.74 & 1.81 & 2.23 & $\mathbf{2 . 2 8}$ & $\mathbf{2 . 4 9}$ & $\mathbf{2 . 0 1}$ & $\mathbf{2 . 0 6 5}$ \\
\hline
\end{tabular}

The amounts of condensate water collected depend directly on room inside humidity and indirectly on the atmospheric (outside) humidity. It is also varying to some extent between day and night and per month where humidity and temperature varies but within a narrow margin. The measured atmospheric humidity has been compared with the recorded humidity provided by timeanddate.com on line site based on data from Bahrain airport (Weather in Manama). The data is tabulated in table 2 and 3 for the two consecutive years. The average values for relative humidity and condensate output were obtained by adding all values and dividing them by the number of recorded readings

Table 2: Comparison between recorded and measured relative humidity and average output collected in 2017

\begin{tabular}{|c|c|c|c|c|c|c|c|}
\hline \multirow{2}{*}{$\begin{array}{l}\text { Month / } \\
2017\end{array}$} & \multicolumn{3}{|c|}{ timeanddate.com } & \multirow{2}{*}{$\begin{array}{l}\text { Average } \\
\text { Humidity \% } \\
\text { Measured } \\
\text { outside }\end{array}$} & \multirow{2}{*}{$\begin{array}{c}\text { Mean } \\
\text { Deviation } \\
\%\end{array}$} & \multirow{2}{*}{$\begin{array}{c}\text { Average } \\
\text { Humidity \% } \\
\text { Measured } \\
\text { Inside }\end{array}$} & \multirow{2}{*}{$\begin{array}{c}\text { Average } \\
\text { output } \\
\text { L/hr }\end{array}$} \\
\hline & $\begin{array}{c}\text { Average } \\
\text { Humidity } \\
\%\end{array}$ & $\begin{array}{c}\text { Max. } \\
\text { Humidity \% }\end{array}$ & $\begin{array}{c}\text { Min. } \\
\text { Humidity } \%\end{array}$ & & & & \\
\hline April & 52 & 84 & 12 & 50.9 & 2.1 & 34.8 & 1.75 \\
\hline May & 42 & 84 & 7 & 43.2 & -2.9 & 34.1 & 1.64 \\
\hline June & 44 & 100 & 13 & 44.9 & -2.1 & 35.6 & 1.83 \\
\hline July & 53 & 89 & 5 & 53.1 & -0.2 & 38.7 & 2.20 \\
\hline Aug. & 59 & 89 & 16 & 58.9 & 0.2 & 42.5 & 2.37 \\
\hline Sept. & 60 & 89 & 7 & 60.5 & -0.8 & 43.4 & 2.28 \\
\hline Oct. & 62 & 94 & 2 & 61.6 & 0.6 & 44.2 & 2.18 \\
\hline Average & 53.14 & 89.86 & 8.86 & 53.3 & -0.44 & 39.04 & 2.036 \\
\hline
\end{tabular}


Table 3: Comparison between recorded and measured relative humidity and average output collected in 2018

\begin{tabular}{|c|c|c|c|c|c|c|c|}
\hline \multirow{2}{*}{$\begin{array}{l}\text { Month/ } \\
2018\end{array}$} & \multicolumn{3}{|c|}{ timeanddate.com } & \multirow{2}{*}{$\begin{array}{c}\text { Average } \\
\text { Humidity \% } \\
\text { Measured } \\
\text { outside }\end{array}$} & \multirow{2}{*}{$\begin{array}{c}\text { Mean } \\
\text { Deviation } \\
\%\end{array}$} & \multirow{2}{*}{$\begin{array}{c}\text { Average } \\
\text { Humidity \% } \\
\text { Measured } \\
\text { Inside }\end{array}$} & \multirow{2}{*}{$\begin{array}{c}\text { Average } \\
\text { output } \\
\text { L/hr }\end{array}$} \\
\hline & $\begin{array}{c}\text { Average } \\
\text { Humidity } \\
\%\end{array}$ & $\begin{array}{c}\text { Max. } \\
\text { Humidity \% }\end{array}$ & $\begin{array}{c}\text { Min. } \\
\text { Humidity } \%\end{array}$ & & & & \\
\hline April & 54 & 89 & 10 & 53.9 & 0.19 & 39.8 & 1.91 \\
\hline May & 47 & 84 & 89 & 46.86 & 0.3 & 37.13 & 1.74 \\
\hline June & 43 & 89 & 12 & 44.84 & -4.3 & 37.15 & 1.81 \\
\hline July & 48 & 89 & 9 & 50.43 & -5.1 & 42.27 & 2.23 \\
\hline Aug. & 53 & 89 & 11 & 54.3 & -2.5 & 42.44 & 2.28 \\
\hline Sept. & 63 & 89 & 11 & 62.05 & 1.5 & 43.69 & 2.49 \\
\hline Oct. & 59 & 94 & 13 & 58.4 & 1 & 40.94 & 1.99 \\
\hline Average & 52.42 & 89 & 22.14 & 52.97 & -1.27 & 40.49 & 2.065 \\
\hline
\end{tabular}

It can be seem that average deviation between the average data of atmospheric humidity provided by the website timeanddate.com [10] and the measured data for the two years period is $1.27 \%$ with maximum value of $5.1 \%$. The measured outside and inside relative humidity showed similar patterns as can be seen in Figure 1 . The inside relative humidity varies between $34.9 \%$ and $44.2 \%$ for 2017 and 37.13 and 43.69 for 2018 with average of 39.04 and $40.49 \%$ respectively. This lay within the thermal environmental comfort conditions mentioned by many investigators. Hundy et al. (2016) said that one of the major applications of the Psychometric Chart in air conditioning is to locate where most humans feel comfortable. This defines the "comfort zone" .They reported that the limitation of this zone found when the temperature is between $22^{\circ} \mathrm{C}$ and $27^{\circ} \mathrm{C}$, and the relative humidity is between $40 \%$ and $60 \%$. This is shown in figure 2 . In the present study, the measured inside room temperature varied between $20 \mathrm{C}$ and $26 \mathrm{C}$ with an average value of 23.4 and $23.6 \mathrm{C}$ for the consecutive two years.

The Atmospheric (outside) and Room (inside) data obtained for the consecutive two years are shown in figure 3 and 4. It can be seen that the amount of collected condensate water depend directly on the inside (indoor) relative humidity and indirectly with the outside (atmospheric) relative humidity. Linear correlation can represent the relationship between the productivity and indoor humidity with mean standard deviation of $0.44 \%$ and $1.27 \%$ for the two consecutive years 2017 and 2018.

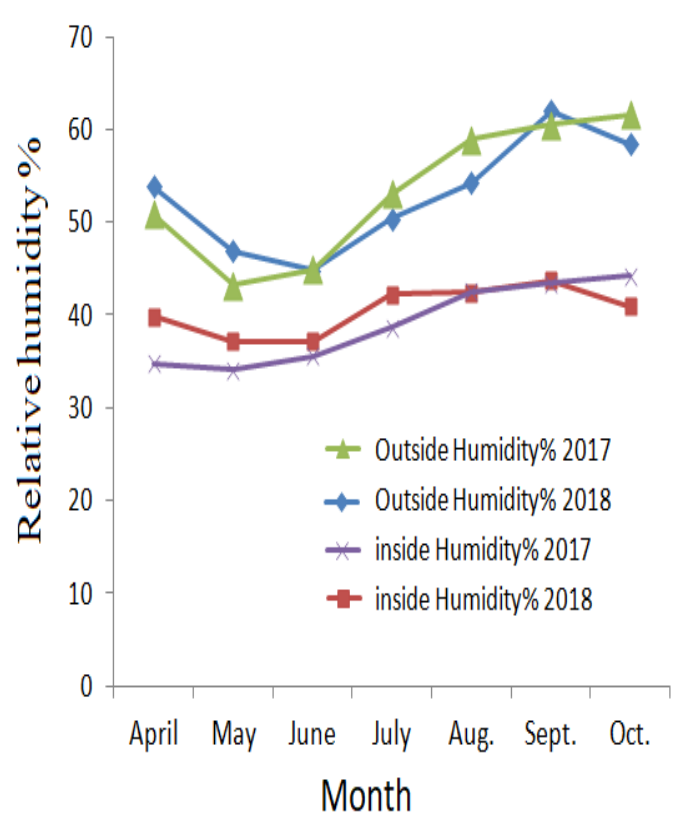

Figure 1. Measured relative humidity for the two year.

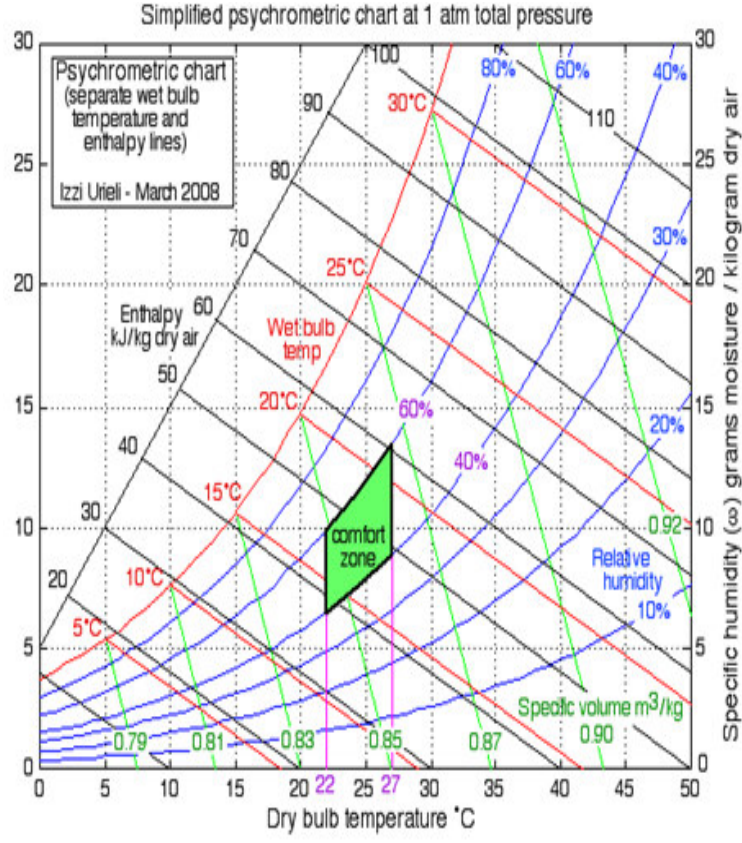

Figure 2. Thermal environmental comfort zone conditions for Human Occupancy [11]. 


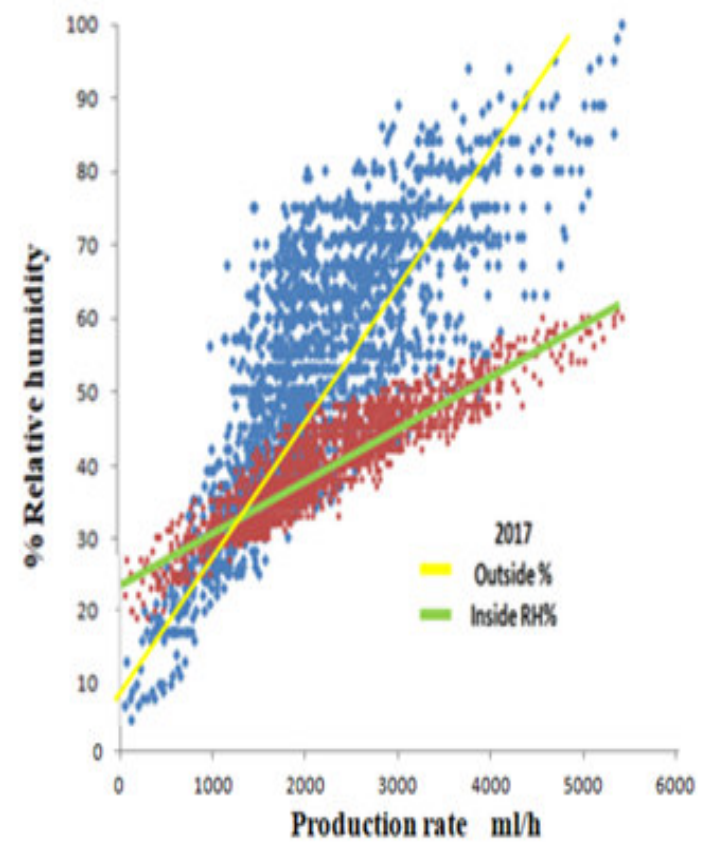

Figure 3. Amount of water collection in 2017

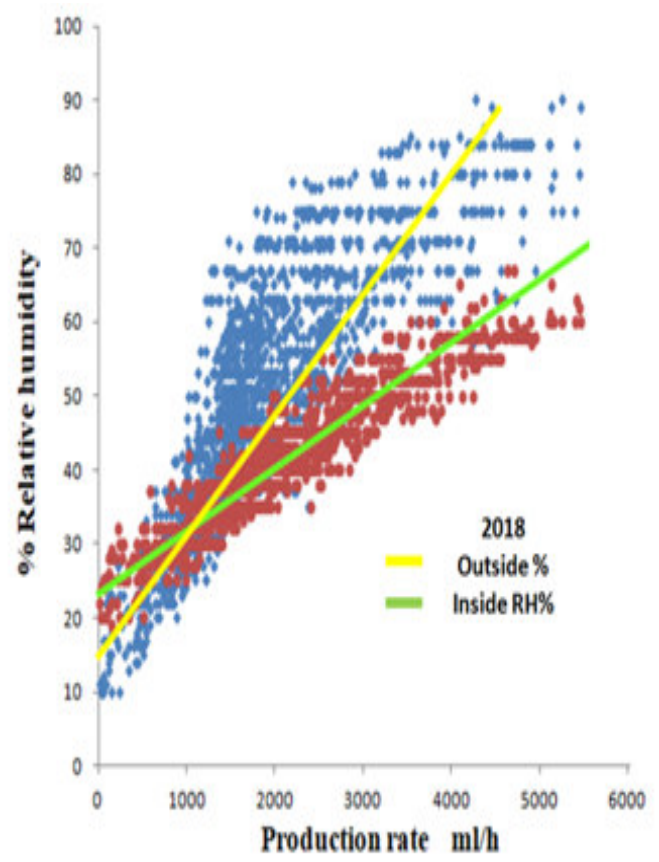

Figure 4. Amount of water collection in 2018

\section{Conclusions}

A substantial amount of over than two litres/hr can be collected from a two-ton air conditioning system during the hot season in the Kingdom of Bahrain. The effect of humidity on the amount collected can be correlated and presented in form of linear relationship. Although the results have been obtained specifically for Bahrain climate condition, but it can be cover other areas especially Arabian Gulf costal area where climate is very similar to Bahrain climate condition in term of humidity and temperature. It could be extended to other coastal areas and even to other climates condition because the study and the collections covered two years period with wide range of humidity and temperatures.

\section{References}

Al-Zubari, W. K., El-Sadek, A. A., Al-Aradi, M. J., and Al-Mahal H.A. (2018). Impacts of climate change on the municipal water management system in the Kingdom of Bahrain: Vulnerability assessment and adaptation options. Climate Risk Management, Volume 20, Pages 95-110.

Attalla, T., and Hunt, L. C. (2016). Modeling residential electricity demand in the GCC countries. Energy Economics 59, 149-158

Bagheri, F. (2018). Performance investigation of atmospheric water harvesting, Water Resources and Industry, 20, $23-28$.

Dalai, P., Nanda, P., Mund, C., Mishra, D., and Gupta, A. (2017). An Experimental Study on Water Harvesting from a Modified Window Air-Conditioner, Energy Procedia 109, 253 - 260.

Hundy, G. F., Trott, A. R., and Welch, T. C. (2016). Chapter 19: Air and Water Vapour Mixtures, Refrigeration, Air Conditioning and Heat Pumps (Fifth Edition), Butterworth-Heinemann, Pages 301-312.

Ghimire, S. R., Johnston, J. M., Garland, J., Edelen, A., and Jahne, M. (2019). Life cycle assessment of a rainwater harvesting system compared with an AC condensate harvesting system, Resources, Conservation and Recycling, Volume 146, Pages 536-548.

Loveless, K. J., and Farooq, A. (2013), Collection of Condensate Water: Global Potential and Water Quality Impacts. Water Resources Management. Volume 27, Issue 5, pp 1351-1361.

Milani, D., Qadir, A., Vassallo, A., Chiesa, M., and Abbas, A. (2014). Experimentally validated model for atmospheric water generation using a solar assisted desiccant dehumidification system, Energy Build. 77, 236-246.

Painter, F.L. (2009). Condensate Harvesting from Large Dedicated Outside Air-Handling Units with Heat Recovery. ASHRAE Transactions 115(2), 573-580.

Weather in Manama, Bahrain https:/www.timeanddate.com/weather/bahrain/manama

Zhao, B., Wang, L.Y., and Chung, T. S. (2019). Enhanced membrane systems to harvest water and provide comfortable air via dehumidification \& moisture condensation. Separation and Purification Technology, Volume 220, Pages 136-144 